\title{
¿HAY UNA LÓGICA DE LAS NORMAS?*
}

Georg Henrik von Wright

La lógica deóntica, nacida en su forma moderna a principios de los cincuenta, ha sido en cierto sentido un hijo problemático en la familia de las teorías lógicas. Sus aspectos problemáticos son, brevemente, los tres siguientes:

a) Dado que generalmente se considera que las normas carecen de valores de verdad o falsedad, ¿cómo puede haber relaciones lógicas como la de contradicción e implicación (consecuencia lógica) entre las normas? Los críticos de la posibilidad de una lógica de las normas suelen llamar a éstas "a-lógicas".

Se ha dicho también que las normas son verdaderas o falsas. Esta tesis quizá pueda ser defendida satisfactoriamente a propósito de algún(os) tipo(s) de normas (el concepto de norma no es fácil de delinear). Sin embargo, las normas como prescripciones de la conducta humana pueden ser consideradas como razonables o irrazonables, justas o injustas, válidas o inválidas a partir de algunos estándares que a, su vez, son también normativos, pero no verdaderas o falsas. Y en buena medida, quizá en su mayoría, las normas son prescripciones.

b) La representación de la estructura conceptual de las normas en un lenguaje formalizado es difícil y controvertida. La mayor parte de los "sistemas" de lógica deóntica se contentan con representaciones muy primitivas y esquemáticas, como es el caso también de este trabajo. Estas representaciones son incapaces de reflejar ciertas distinciones relativas a la noción de acción humana, que a su vez pueden ser relevantes para establecer ciertas diferencias entre normas. Por ejemplo, la distinción entre no hacer una cier-

* Trad. de Daniel González Lagier. Título original "Is there a Logic of Norms?”, en Six Essays in Philosophical Logic, Acta Philosophica Fennica, vol. 60, 1996, págs. 35-53. 
ta acción y hacer lo opuesto a esa acción. Una representación correcta de la estructura conceptual de las normas debe basarse en una representación correcta de la estructura conceptual de las acciones (de la conducta). Otra dificultad desconcertante en este ámbito es la cuestión de cómo representar correctamente en un lenguaje formal a las normas condicionales, esto es, las normas que prescriben qué debe, puede o no debe ser hecho dadas ciertas condiciones.

c) Una tercera controversia acerca de la lógica deóntica es la relativa a su aplicabilidad y utilidad como un instrumento para clarificar y describir la estructura de los sistemas normativos reales, tales como, por ejemplo, un ordenamiento jurídico. ¿Qué papel puede cumplir -si es que cumple algunoun sistema de lógica deóntica en la clarificación de cuestiones tan relevantes como las "lagunas" y las "contradicciones" en el Derecho?

Los problemas del epígrafe (a) pueden ser considerados filosóficos o pertenecientes a la filosofía de la lógica; los del epígrafe (b), por su parte, pueden considerarse problemas lógicos o pertenecientes a la lógica formal. Los problemas del tercer grupo son, fundamentalmente, problemas de filosofía moral o jurídica, particularmente de la primera.

Las cuestiones discutidas en este trabajo pertenecen fundamentalmente al grupo (a) y, en menor medida, al (c). El objetivo de este artículo es discutir si es posible -y en qué medida- una lógica de las normas.

Con fines comparativos, en lo que sigue haré referencia a lo que llamo el sistema "clásico" o "estándar" de lógica deóntica. Este nombre, sin embargo, no tiene un significado unívoco. Pueden reclamarlo al menos las siguientes tres "lógicas deónticas":

a) El sistema de lógica deóntica de mi trabajo en Mind. Sus ingredientes formales fueron dos operadores deónticos, " $O$ " para la obligación y " $P$ " para la permisión; las conectivas usuales, simbolizadas $\sim, \&, \mathrm{~V}, \rightarrow, \leftrightarrow$, y las variables $p, q, \ldots$ Las variables representaban categorías o tipos de acciones humanas, tales como, por ejemplo, homicidio o robo. En esta concepción de las variables, las fórmulas que contienen operadores deónticos iterados no son fórmulas bien formadas. Y la aplicación de las conectivas para formar compuestos de variables plantea también problemas.

b) Un sistema con los mismos ingredientes pero con una diferente concepción de las variables. Las variables se consideran ahora, a la manera estándar, como representaciones esquemáticas de oraciones. De esta manera, la iteración de operadores está permitida y la aplicación de conectivas no parece problemática ( $\sin$ embargo, véanse más adelante las secciones $8 \mathrm{y}$ 18). 
c) A la vista de las dificultades de interpretar las fórmulas con operadores iterados y por algunas otras razones, puede ser conveniente considerar el sistema "clásico" de lógica deóntica como limitado a las fórmulas de primer orden, esto es, fórmulas sin iteración, del sistema (b). Ahora el sistema es, desde el punto de vista formal, idéntico al sistema (a), la única diferencia entre ellos está en la interpretación de las variables.

Puede pensarse que el sistema (b) presenta obvias ventajas sobre (a) dado que supera algunas de sus dificultades y restricciones. Pero si lo que se pretende es dar cuenta de ("hacer justicia a") las estructuras normativas reales, la concepción original de las variables de (a) puede considerarse más "realista".

En lo que sigue, cuando se mencione el sistema "clásico" de lógica deóntica se hará referencia al sistema (c) de los referidos arriba. Las variables, $p$, $q$, etc., serán representaciones esquemáticas de oraciones. Asumiré que estas oraciones expresan lo que podemos llamar estados de cosas. Tales estados serán del tipo de lo que en otro lugar he llamado genéricos, esto es, estados que pueden darse o no en determinadas ocasiones (en el espacio y /o en el tiempo). Por ejemplo, que una ventana está abierta es un estado genérico. La oración que lo describe no dice por sí misma algo que sea verdadero o falso. Por el contrario, la oración "la ventana (en mi habitación) está abierta ahora (en el momento en que estoy escribiendo)" es verdadera o falsa.

En lugar de decir que las variables representan oraciones describiendo estados genéricos, abreviaré diciendo que las variables representan estados. De este modo, hablaré, por ejemplo, del estado $p$ y evitaré la expresión -más correcta pero también más engorrosa- "el estado de que $p$ ".

$O p$ y $P p$ son representaciones esquemáticas de oraciones expresando lo que propongo llamar, simplemente, normas-O y normas- $P$, respectivamente. Para simplificar, sin embargo, trataré esas expresiones como representaciones de normas. Así, hablaré de la norma $O p$ y de la norma $P p$.

Tomemos, por ejemplo, la norma $O p$, de acuerdo con la cual el estado de cosas $p$ debe ser (existir, tener lugar). ¿Qué relación tiene esto con las acciones humanas? Es fácil observar que la norma cubre diferentes casos. Si el estado de cosas $p$ no está presente y no va a tener lugar -podríamos decir"por sí mismo", la norma requiere que nosotros lo produzcamos, esto es, que cambiemos la situación de $\sim p$ a $p$. Si, por el contrario, el estado está presente y no desaparece "por sí mismo", lo prescrito es dejar que $p$ permanezca, esto es, no destruirlo; la norma prohíbe, en otras palabras, la destrucción de $p$. Pero también hay otros supuestos cubiertos por $O p$. Supongamos que $p$ está presente pero desaparecerá si no interferimos. Entonces la norma nos impo- 
ne evitar que $p$ desaparezca. Por el contrario, si $p$ no existe pero aparecerá a menos que lo impidamos, entonces la norma requiere que dejemos que esto suceda, esto es, prohíbe impedir $p$.

No es necesario que el emisor de la norma exija los cuatro casos cubiertos por $O p$. Puede querer que evitemos que $p$ desaparezca y que dejemos que llegue a ser si lo hace con independencia de nuestra intervención; pero puede que no quiera que hagamos el esfuerzo de producir $p$ a menos que tenga lugar "por sí mismo". Hay 15 combinaciones posibles por medio de las cuales una autoridad normativa puede desear que sea el estado de cosas $p$, pero esas distinciones no pueden expresarse con el simbolismo que usamos aquí.

Con nuestro simbolismo primitivo, además, no podemos expresar $a$ quién está dirigida una norma determinada, ni quién la ha emitido. Cuando varias normas coincidan en un mismo contexto, se asumirá tácitamente que han sido emitidas por la misma "autoridad" y dirigidas a los mismos "sujetos destinatarios".

Las anteriores observaciones deberían recordarnos qué lejos de las estructuras normativas reales queda un sistema de lógica deóntica del tipo de los "clasicos" (en cualquiera de sus variantes). Pero no tenemos que perder la esperanza de superar esas insuficiencias. Se han hecho varios esfuerzos más o menos satisfactorios para resolverlas, aunque todavía no se ha alcanzado el objetivo.

\section{4}

Consideremos una norma-O o una norma- $P$. Llamaré contenido de la norma al estado de cosas que declara obligatorio o permitido. La representación simbólica de un contenido normativo es una variable, $p, q, \ldots$ o un compuesto molecular de variables.

Las formas lógicamente equivalentes de la misma representación simbólica deberían contar como el mismo contenido normativo. A menudo, es conveniente presentar el contenido normativo mediante lo que suele llamarse su forma normal disyuntiva perfecta, esto es, como una disyunción de conjunciones de todas las variables y/o sus negaciones. Por ejemplo, la obligación disyuntiva $O(p v q)$ es equivalente a $O(p \& q v p \& \sim q v \sim-p \& q)$.

Pueden introducirse vacuamente nuevas variables en la representación simbólica de los contenidos normativos, que no resultan afectados por estas transformaciones formales. Por ejemplo: el contenido normativo de $O P$ es el mismo que el de $O(p \& q v p \& \sim q)$. 
Llamaré estado realizable a un estado de cosas que puede ser producido o destruido, evitada su aparición o -si está presente- evitada su desaparición. Un estado es realizable cuando su producción o no producción en una ocasión dada puede ser el resultado de una acción humana.

Un estado puede ser realizable sólo en alguna o algunas de las cuatro formas mencionadas. Por ejemplo, puede que sea posible producirlo pero no destruirlo. Dado que aquí no distinguimos los cuatro casos con nuestro simbolismo, trataré de ignorar estas limitaciones de realizabilidad.

Lo que un hombre puede hacer, otro puede no ser capaz de hacerlo. La noción de un estado que es "realizable" es, por tanto, relativa a la capacidad humana, que puede variar de persona a persona. Aquí también serán ignoradas estas variaciones en la realizabilidad.

Un estado de cosas cuya producción en una ocasión dada es o bien necesaria o imposible no es un estado realizable. Esta imposibilidad puede ser lógica, física o humana (la necesidad es la imposibilidad de lo opuesto; la necesidad de $p$ es la imposibilidad de $\sim p$ ). Aquello que es lógicamente imposible es también física y humanamente imposible, pero algo que es humanamente imposible puede ser física o lógicamente posible.

Por una norma genuina (de conducta humana) entenderé una norma- $O$ o una norma- $P$ cuyo contenido es (un estado) realizable. A una norma cuyo contenido es necesario o imposible la llamaré espuria.

La única manera de expresar el carácter no realizable de un contenido normativo en el simbolismo primitivo que estamos usando consiste en adoptar la forma de una contradicción o tautología de la lógica proposicional. Así, por ejemplo, $O(p \& \sim p)$, que exige algo imposible, o $P(p v-p)$, que permite algo necesario, son normas genuinas, pero espurias.

En la "vida real", sin embargo, este carácter no realizable es entendido de una manera mucho más amplia. La realizabilidad no sólo debe ser lógicamente contingente, sino también físicamente. Sólo lo que no es ni físicamente necesario ni físicamente imposible puede ser realizado por el hombre. Es por tanto natural y razonable decir de cualquier norma que obliga o permite algo no realizable que es "espuria", que no es una "norma real".

En este punto quisiera señalar algo acerca de lo que podría llamarse la relatividad de las nociones de necesidad y posibilidad.

En la lógica clásica, $p \& \sim p$ es algo imposible, algo que rechazamos como necesariamente falso. De la misma forma, en esta lógica $p v-p$ es aceptado como una verdad necesaria. Pero en las lógicas no clásicas del tipo de las intuicionistas o paraconsistentes las cosas son diferentes.

La mayoría de los sistemas de lógica deóntica se construyen con una base clásica. Pero hay otras maneras de construirlos. Por ejemplo, dentro 
de una lógica deóntica paraconsistente la noción de realizabilidad se ve de manera diferente. Y viéndola así quizá podamos ajustarnos a la manera en la que a veces entendemos esta noción en la "vida real". Una orden con la forma $O(p \& \sim p)$ no es por tanto incondicionalmente espuria.

Aunque tales concepciones no serán consideradas en este trabajo, es bueno estar al tanto de ellas.

\section{6}

Consideremos un conjunto (finito) de normas- $O$ y normas- $P$. Asumiremos que todas las normas del grupo son genuinas.

Explicaré ahora qué significa que este conjunto es (in)consistente.

Consideremos primero dos normas- $O$ del grupo. Diré que son mutuamente consistentes sí, y sólo sí, la conjunción de sus contenidos es un estado de cosas realizable. Si no son consistentes, son inconsistentes o mutuamente contradictorias. Por ejemplo, $O p$ y $O \sim p$ son mutuamente inconsistentes, porque $p \& \sim p$ es un estado de cosas imposible.

Esta noción de consistencia puede generalizarse. Un conjunto de $n$ normas- $O$ genuinas es consistente si la conjunción de sus contenidos es ejecutable; en caso contrario, es inconsistente. Consideremos, por ejemplo, las siguientes tres normas- $O$ : $O \sim p, O(p v q)$, y $O \sim p$. Dos cualesquiera de ellas pueden ser mutuamente consistentes, pero el conjunto de las tres es inconsistente. Esto es así porque $\sim p \&(p v q) \& \sim q$ es una contradicción en lógica proposicional.

Cualquier conjunto de normas- $P$ genuinas es, por definición, consistente. En otras palabras, las normas- $P$ no pueden contradecirse entre sí. Sus contenidos pueden ser mutuamente contradictorios, como en $P p$ y $P \sim p$. Este es un supuesto muy común: normalmente, si un estado de cosas está permitido, el estado contradictorio está también permitido. No hay contradicción en esto.

Una norma- $P$ genuina, sin embargo, puede entrar en contradicción o ser inconsistente con una norma- $O$ genuina o un conjunto consistente de normas- $O$ genuinas. Esto sucede cuando la conjunción del contenido de la norma- $P$ con el contenido de la norma- $O$ o con la conjunción de todos los contenidos de las normas- $O$ del grupo no es un estado realizable. Para dar un ejemplo muy simple: $P \sim p$ y $O p$ son mutuamente inconsistentes (la obligatoriedad de un estado es inconsistente con el permiso del estado contrario).

Si una norma- $P$ es consistente con un conjunto consistente de normas- $O$, el conjunto formado por esta norma- $P$ y todos los miembros del conjunto de normas- $O$ también es consistente.

Ahora podemos proponer la siguiente definición: Un conjunto de normas- $O$ genuinas y normas- $P$ genuinas es consistente si, y sólo si, el sub- 
conjunto formado por todas las normas- $O$ es i) él mismo consistente y ii) consistente con cada uno de los miembros (individuales) del subconjunto formado por todas las normas- $P$.

Cuando llamamos a dos proposiciones mutuamente contradictorias normalmente queremos decir que no pueden ser simultáneamente verdaderas, y cuando llamamos consistente a un conjunto de proposiciones queremos decir que todas ellas pueden ser (simultáneamente) verdaderas.

Pero las normas del tipo de las prescripciones no tienen valores de verdad. Por tanto, este análisis de las nociones de consistencia y contradictoriedad no es aplicable a las normas. ¿Son entonces arbitrarias las definiciones de la sección anterior? ¿Cómo deberían ser "justificadas" si no es en términos de valores de verdad?

$p y \sim p$ son mutuamente contradictorios. Pero ¿por qué debemos considerar de la misma forma a $O p$ y $O \sim p$ ? Una posible respuesta: Un emisor de normas que exige que uno y el mismo estado de cosas sea y no sea a la vez no puede ver satisfecha su pretensión. Está "pidiendo la luna". Su requerimiento es irracional.

¿Por qué son $O p$ y $P \sim p$ mutuamente contradictorios (inconsistentes)? El destinatario de la norma que es obligado a hacer que $p$ y al que se le permite hacer que $\sim p$ no podrá cumplir su deber o usar su permiso. El emisor de una norma que requiere que algo sea y al mismo tiempo permite el estado contradictorio seguramente nos parecerá irracional o extraño.

¿Por qué no son $P p$ y $P \sim p$ mutuamente contradictorios o conflictivos? Si me dijeran que puedo hacer que $p$ pero también que $\sim p$ no me sentiría desconcertado. Normalmente entendería que esto quiere decir que yo puedo escoger o que "está en mi mano" producir un estado o el otro (pero no entendería que significara que se me permite producir ambos al mismo tiempo). El emisor de los permisos no se comporta de manera irracional. Simplemente me indica que "no le corresponde a él" si hago una cosa o la otra o ambas.

Que varias normas- $O$ son consistentes implica, a su vez, que lo que exigen puede ser conjuntamente satisfecho. El "acierto" de unir las obligaciones puede discutirse, pero ¿alguien pondría en duda su fundamento lógico? Seguramente no.

Que varias normas- $P$ no pueden ser inconsistentes se manifiesta en el hecho de que si sus contenidos entran en conflicto quien tiene el permiso es libre de elegir cuál de los contenidos en conflicto va a realizar.

En estas consideraciones, con las que pretendo justificar nuestras definiciones de consistencia y contradicción normativas, se ha hecho referencia a la 
racionalidad de exigir y permitir ciertas cosas en conjunción con alguna otra. Pero en ellas hay también una referencia indirecta a la verdad. Los estándares de racionalidad para emitir algunas normas están constituidos por la posibilidad o imposibilidad de que los contenidos normativos sean conjuntamente verdaderos. En este sentido, puede decirse que las nociones de consistencia y contradicción normativas son secundarias respecto de las nociones de consistencia y contradicción de proposiciones verdaderas o falsas.

Se podría objetar lo siguiente: El hecho de que las normas carezcan de valores de verdad hace imposible aplicarles las nociones de consistencia y contradicción. Que $p$ contradice $\sim p$ no es una buena razón para sostener que $O p$ contradice $O \sim p$. Y dado que la consistencia y la contradicción no se aplican a las normas, no hay (no puede haber) una lógica de las normas.

Decir esto implicaría adoptar una actitud extremadamente conservadora acerca de qué es la lógica. Creo que esta actitud no está justificada. Pero también creo que la mayoría de los lógicos la asumen sin más cuando acríticamente, como cuestión de hecho", aplican a las normas las nociones problemáticas que hemos estado discutiendo.

\section{8}

Otro "pecado" que los lógicos deónticos han tendido a cometer es no haber prestado suficiente atención al problema de cómo aplicar a los enunciados que expresan normas las conectivas oracionales "y", "o", "no" y aquellas que son definibles en términos suyos. Uno de mis propósitos con este trabajo es "expiar" este "pecado".

Se podría formular un Test de Aplicabilidad de las conectivas oracionales, más o menos como sigue: Los compuestos formados por oraciones y conectivas deben tener el mismo carácter lógico que las oraciones mismas.

Un ejemplo: Los compuestos de oraciones (que expresan proposiciones) con un valor de verdad son a su vez oraciones (que expresan proposiciones) con un valor de verdad. Sobre esta idea se funda la noción de función de verdad. Las propias conectivas reciben usualmente el nombre de conectivas veritativas.

Que las normas satisfagan el anterior test podría significar lo siguiente: un compuesto de oraciones que expresan normas ("formulaciones normativas") es a su vez una oración que expresa una norma.

Las normas son obligaciones, permisos o prohibiciones, esto es, constituyen obligaciones, permisos o prohibiciones. Por tanto, si las formulaciones normativas, cuando se unen por medio de conectivas oracionales, expresan normas, debe ser posible identificar su unión como una obligación, una permisión o una prohibición. ¿Es esto (siempre) posible? 
Es importante darse cuenta de la siguiente ambigüedad: Una formulación normativa, tal como, por ejemplo, "debe ser el caso de que_" o "puede ser el caso de que _" puede usarse prescriptivamente para enunciar una norma o descriptivamente para afirmar que cierta norma ha sido formulada (emitida, que "existe"). Cuando se usa descriptivamente, las formulaciones normativas expresan proposiciones verdaderas o falsas, generalmente llamadas "proposiciones normativas". La aplicación de conectivas oracionales (conectivas veritativas) no plantea en este caso problemas, a diferencia de lo que ocurre cuando las formulaciones normativas expresan normas.

Consideremos primero la conectiva "y".

Tomemos la oración compleja $O p \& O q$, es decir, "debe ser el caso de que $p$ y debe ser el caso de que $q$ ". Cuando es usada descriptivamente se refiere a la proposición -verdadera o falsa, según el caso- de que hay (existe) una norma imponiendo que $p$ y una norma imponiendo que $q$. ¿Puede esta oración compleja ser también interpretada prescriptivamente? La respuesta parece ser afirmativa. Interpretada prescriptivamente, la oración expresa una norma- $O$ de acuerdo con la cual debe ser el caso de que $p$ y $q$. El contenido de la norma así expresada es la conjunción de los contenidos de las normas expresadas por separado por "debe ser el caso de que $p$ " y "debe ser el caso de que $q$ ". Se podría decir que este hecho queda reflejado en el teorema de la lógica deóntica "clásica" $O p \& O q \leftrightarrow O(p \& q)$.

Tomemos el compuesto $P p \& P q$, "permitido el caso de que $p$ y permitido el caso de que $q$ ". La oración puede usarse para afirmar que hay (existen, han sido promulgadas) dos normas permisivas, pero sería un error creer que puede ser usada para emitir un permiso. El permiso conjunto $P(p \& q)$ no es equivalente a la conjunción de los permisos $P p$ y $P q$. Es posible que los dos estados estén individualmente permitidos y simultáneamente que esté prohibido su contenido conjunto. $P p \& P q \leftrightarrow(p \& q)$ no es un teorema de la lógica deóntica "clásica".

Por tanto, "y" en $P p \& P q$ sólo puede tener una función descriptiva (para informar a los destinatarios de las normas o a cualquiera de la existencia de dos permisos), y no prescriptiva (para extraer una nueva norma de dos normas dadas). Lo mismo es verdad de la conjunción $O p \& P q$. Establece que una cierta cosa es obligatoria y otra está permitida, pero no crea una norma "híbrida" de una que obliga y otra que permite hacer algo. En definitiva: la combinación de formulaciones normativas por medio de la conectiva "y" implica una oración que afirma el hecho de que las normas enunciadas por esas formulaciones han sido promulgadas (son, existen). Esto es así también para formulaciones de normas- $O$ unidas por "y". Pero, por algo que propongo llamar un "accedente semántico", la norma $O(p \& q)$ también puede ser formulada, duplicando la "O", con la forma $O p$ y $O q$. 
Consideremos ahora la negación.

El enunciado "no es obligatorio que $p$ " o "no es el caso que deba ser el caso que $p$ " es ambiguo. Puede ser entendido en el sentido de que no ha sido promulgada (no hay, no existe) ninguna norma imponiendo que $p$. Así entendida, la oración es un enunciado de hecho relativo a qué normas existen o no existen. Pero la misma oración puede ser interpretada también con el significado de que está permitido que sea el caso que no $p$. Entendida de esta manera, la oración enuncia una norma permisiva.

De manera similar, la oración "no está permitido que $p$ " o "no es el caso que esté permitido el caso que $p$ " puede ser interpretado como una prohibición del estado $p$ o, alternativamente, como una indicación de que el estado en cuestión simplemente no ha sido permitido. En el primer caso la oración enuncia una norma; en el segundo caso afirma un hecho acerca de normas.

Para evitar estas ambigüedades introduciré la noción de norma-negación de una norma dada y diré que la negación de una obligación es un permiso con contenido opuesto, y que la negación de un permiso es una obligación con contenido opuesto. Así, $P \sim p$ es la norma-negación de $O p$, y $O \sim p$ la norma-negación de $P p$.

El término "no" tiene, por tanto, dos aplicaciones en las formulaciones normativas. Una es la de negar que exista una norma expresada en esas palabras. La otra es la de pasar del enunciado "no obligatorio que" a "permitido que no" y de "no permitido que" a "obligatorio que no" (la conectiva, por tanto, se desplaza desde delante de la formulación de la norma a estar situada delante de la formulación del contenido normativo). La negación de una oración que enuncia una norma implica otra oración que enuncia una norma sólo en la segunda de estas aplicaciones.

\section{0}

Consideremos, por último, la conectiva "o".

"Debe ser que $p o$ debe ser que $q$ ". La manera natural de entender este enunciado es como si nos dijera que uno de los dos estados en cuestión debe ser, ha sido declarado obligatorio, pero sin especificar cuál. Por tanto, no nos dice qué norma ha sido emitida.

También es posible interpretar el anterior enunciado como expresando una norma de acuerdo con la cual debe producirse el estado de cosas $p v$ $q$. Pero esta interpretación no parece muy normal. Comparemos con "Debe ser que $p o$ está permitido que $q$ ". Esto sólo podría usarse para afirmar, de manera verdadera o falsa, que existe una determinada norma- $O$ o una norma determinada norma- $P$, sin decirnos cuál de las dos alternativas es el caso. 
Tomemos ahora "Está permitido que $p$ o está permitido que $q$ ". La forma más natural de entender esto es como la afirmación de que uno de los dos permisos ha sido emitido. Pero también podría interpretarse, sin que resultara poco natural, como la enunciación de una permisión con el contenido disyuntivo $p v q$ (porque $P(p v q) \leftrightarrow P p v P q$ es un teorema de la lógica deóntica clásica).

Como hemos visto, en ocasiones, de acuerdo con nuestras "intuiciones lingüísticas", desplazamos una conectiva oracional que se aplica a las formulaciones normativas de manera que se aplique a los contenidos normativos: de "debe ser_y debe ser _" pasamos a "debe ser _ y _"; de "no debe ser _" pasamos a "está permitido no _"; de "no está permitido _" pasamos a "debe ser no _"; y de "está permitido_o está permitido _" pasamos a "está permitido _o _". Pero en todos los casos, cuando las conectivas oracionales se usan para formar complejos de formulaciones normativas, tanto en los casos en los que el desplazamiento puede hacerse (sin distorsionar su significado)) como en los casos en los que no, las fórmulas complejas tienen una interpretación natural como expresiones de enunciados verdaderos o falsos acerca de que tales normas- $O$ y/o tales normas- $P$ existen (han sido emitidas, pertenecen a un cierto "código", etc.). Por esta razón, llamaré a la posibilidad del desplazamiento un "accidente semántico" y diré que el uso genuino de las conectivas oracionales al construir formulaciones normativas complejas consiste en afirmar hechos y no en expresar normas. El uso de conectivas oracionales para construir formulaciones normativas complejas no cabe en una genuina "lógica de las normas".

También pueden tener cabida aquí algunas observaciones sobre las conectivas y las oraciones imperativas.

"¡Abre la ventana $y$ cierra la puerta!", "¡Abre la ventana $o$ cierra la puerta", "No abras la vantana!", "¡No abras la vantana y no cierres la puerta", son oraciones bien formadas (gramaticalmente). En "términos deónticos", la primera dice que debe ser que la ventana esté abierta $y$ la puerta cerrada; la segunda dice que debe ser que la ventana esté abierta $o$ la puerta cerrada; la tercera, que debe ser que la ventana no esté abierta; y la cuarta, que debe ser que la ventana no esté abierta $o$ que la puerta no esté cerrada.

Todas las oraciones imperativas complejas son, por tanto, de un tipo que, al ser traducidas a un vocabulario normativo, permiten desplazar las conectivas desde delante de la formulación normativa hasta delante del contenido normativo (de la formulación del contenido normativo).

\section{1}

Tomemos un conjunto consistente compuesto por normas (genuinas) y una norma- $O$ o una norma- $P$ (genuina). Añadamos al conjunto la norma ne- 
gación de esa norma adicional. Asumamos que el conjunto así compuesto es inconsistente. Cuando esto sea así, diré que el conjunto original de normas implica la norma- $O$ o norma- $P$ cuya norma-negación hace que el conjunto sea inconsistente. También puede decirse que la norma derivada es una norma-consecuencia lógica de las normas del conjunto.

Veamos algunos ejemplos. Supongamos el conjunto compuesto por una única norma $O p$ y supongamos la norma adicional $P p$. La norma-negación de esta última es $O \sim p$. Ésta se contradice con $O p$, esto es, el conjunto compuesto por $O p$ y $O \sim p$ es inconsistente. Por tanto, $O p$ implica $P p$. "Obligatorio" implica "permitido"; lo que es obligatorio, necesariamente está también permitido.

Tomemos un conjunto formado por dos normas, $P p$ y $O(\sim p v q)$. Añadamos $O \sim q$. El conjunto de las tres normas, $P p, O(\sim p v q)$ y $O \sim q$ es inconsistente. Esto es así porque $p \&(\sim p v q) \& \sim q$ es una contradicción en lógica proposicional. Por tanto, las normas $P p$ y $O(\sim p v q)$ implican conjuntamente la norma-negación de $O \sim p$, que es $P \sim \sim q$, es ecir, $P q$.

$\sim p v q$ equivale, por definición, a la implicación material $p \rightarrow q$. Por lo tanto, puede decirse que la anterior implicación queda reflejada en el siguiente teorema de la lógica deóntica clásica: $P p \& O(p \rightarrow q) \rightarrow P q$. Esto a veces se expresa diciendo que hacer algo permitido sólo puede comprometernos a hacer cosas que están asimismo permitidas. Tomado cum grano salis puede decirse que se trata de una verdad de la lógica de las normas. Tiene una interesante caso opuesto según el cual uno sólo puede verse comprometido (obligado) a hacer algo ilícito si previamente ha realizado un acto ilícito (el " Teorema de Jepthah" de la lógica deóntica).

$O(p \& q)$ implica $O p$. Esto se sigue del hecho de que la norma-negación de $O p$, que es $P \sim p$, es inconsistente con $O(p \& q)$.

Ahora sustituyamos "q" por " $p$ " en $O(p \& q)$. ¿Diremos que $O(p \& \sim p)$ también implica $O p$ ? El conjunto cuyo único miembro es $O(p \& \sim p)$ es inconsistente; por ello este caso no está cubierto por nuestra anterior definición de implicación.

Se podría aceptar esta derivación sobre la base de que la implicación entre $O(p \& q)$ y $O p$ es válida para todos los "valores" de las variables "p" y " $q$ " y que la contradicción entre $p \& q$ y $\sim p$ existe independientemente de la sustitución de " $q$ " por " $\sim p$ " (la sustitución no afecta a la implicación). Éste parece un argumento sólido. No hay un argumento correspondiente para defender una implicación también entre $O(p \& \sim p)$ y $O q$, lo que parecería absurdo. No obstante, si debe aceptarse que $O(p \& \sim p)$ implica o no $O p$ parece una cuestión de escasa imporancia para la lógica deóntica.

Un último supuesto. $O p$ implica $O(p v q)$. Esto es así porque, si se exige que sea el caso de que $p$, entonces no es posible, de manera consistente, 
que se permita también que $\sim p$ sea el caso en conjunción con algo más $(P(\sim p \& \sim q))$. Si ordeno que sea enviada una carta, no puedo consistentemente con esto permitir que no sea enviada sino quemada. ¡Por tanto, al exigir que sea enviada, he ordenado que sea enviada $o$ quemada! Esta es la famosa paradoja señalada por el filósofo del Derecho danés Alf Ross. Ross usó la paradoja como un argumento contra la posibilidad de una lógica de las normas. Después volveremos sobre la cuestión y mostraré que la paradoja es completamente inocua.

Un lógico con una actitud cautelosa podría objetar: ¿Qué "derecho" tenemos para llamar "implicación" a la relación definida en la sección anterior? Es manifiesto que las normas prescriptivas no son verdaderas o falsas. Dado que, por tanto, que una norma implica otra no puede querer decir que si la primera es verdadera, entonces la segunda es necesariamente verdadera, ¿qué puede querer decir? Ya hemos señalado la respuesta: significa que la primera norma es inconsistente con la norma-negación de la segunda. Pero -replica nuestro prudente lógico- esta noción de inconsistencia no es la normal en lógica, esto es, la necesaria falsedad de una conjunción, sino que la hemos explicado en términos de una idea de racionalidad relativa a consideraciones acerca de los propósitos de la actividad normativa. Esto es ciertamente así, pero la analogía con la contradicción y la inconsistencia entre proposiciones verdaderas o falsas parece perfectamente natural y acorde con la forma en que hablamos acerca de normas. Y lo mismo ocurre con nuestra extensión analógica de la noción de implicación.

Nuestro lógico cauteloso, si todavía no está convencido, puede aún insistir y decir que las nociones que estamos usando no son las de contradicción e implicación lógicas, sino sólo análogas a ellas, que se aplican a entidades que por naturaleza son a-lógicas. A lo cual le podría contestar que éste uso de "lógica", sencillamente, es demasiado estricto. Rehusar aceptar que una obligación implica lógicamente el permiso correspondiente es, simplemente, terquedad.

Pero hay que advertir del peligro de un equívoco con nuestra noción de implicación: Que una norma implica otra no quiere decir que si la primera "existe" entonces la segunda "existe" también, a menos que tomemos la palabra "existe" en algún sentido especial y quizá no muy común. Una norma que dice que algo debe ser puede existir perfectamente sin una norma que diga que esa misma cosa está también permitida. Que la segunda es "implicada" por la primera sólo significa que un intento por parte del emisor de la norma de prohibir esa acción provocaría una "contradicción", en el sentido 
de que no sería posible satisfacer su exigencia. Y si esto no es "ilógico" en sentido estricto, al menos es irracional en un sentido casi paradigmático.

13

Supongamos un conjunto de normas que han sido dirigidas al mismo sujeto (o sujetos) y que proceden de una y la misma fuente (autoridad normativa, legislador). Llamaré a este conjunto un código normativo.

Asumamos ahora que encontramos que el conjunto es inconsistente. Existe, por tanto, una "contradicción en el Derecho". Esto no es algo poco común en la "vida real".

Dado que la inconsistencia (contradicción) significa aquí que no puede hacerse todo lo requerido o que puede hacerse todo lo requerido pero es imposible realizar algo permitido, este estado de cosas puede considerarse insatisfactorio. El legislador quizá quiera dar algún paso para resolver la inconsistencia.

En el caso más simple, la inconsistencia estará provocada por la coexistencia de dos normas- $O$ que están mutuamente en conflicto o por el conflicto entre una norma- $O$ y una norma- $P$.

La "lógica" no puede ayudarnos a resolver el conflicto, pero puede haber alguna regla o principio normativo, alguna "metanorma", que nos diga cómo hacerlo. Si las normas del conjunto han sido emitidas en momentos diferentes, la regla podría ser que la norma anterior de las que están en conflicto sea "expulsada" del código, derogada por la norma posterior. En la Teoría del Derecho esta regla se expresa como lex posterior derogat legi anteriori.

Pero podríamos imaginar también una metanorma para resolver conflictos opuesta, "conservadora", que dijera que la norma anterior deroga a la norma posterior que entra en conflicto con ella. Se puede imaginar fácilmente que ambas metanormas sean usadas en el mismo ordenamiento jurídico: una para un subconjunto del código y otra para otro.

Un caso más complicado de "contradicción en el Derecho" se produce cuando no son dos las normas que se contradicen, sino tres o cuatro o más. Éste sería el caso, por ejemplo, si $P p, O(p \rightarrow q)$ y $O \sim q$ coexistieran en el mismo código. Si alguna de ellas es una "recién llegada" que provoca la inconsistencia, el principio lex posterior nos dice sólo que una u otra de las más antiguas debe ser revocada, pero no nos dice cuál. Esto tendría que concretarse con algún otro tipo de metanorma, o con una decisión arbitraria.

Sin embargo, si las normas son promulgadas simultáneamente, no puede apelarse ni al principio lex posterior ni al principio lex anterir. Para estos casos se podría imaginar una metanorma de acuerdo con la cual las normas$O$ derogan a las normas- $P$ en caso de conflicto; pero también se podría imaginar una metanorma contraria que estableciera a los permisos por encima 
de las obligaciones ("garantizar la libertad por encima del deber"). Puede haber todavía otros principios para resolver los conflictos normativos, o puede dejarse el caso a decisiones arbitrarias. Supongo que en la práctica los conflictos se resuelven a menudo con algunas modificaciones de las normas en conflicto, restringiendo su contenido hasta que la contradicción sea eliminada.

\section{4}

Diré que un estado de cosas está deónticamente determinado si, y sólo si, está o bien prohibido o bien permitido. Como la obligatoriedad implica la permisión, también los estados obligatorios están deónticamente determinados en este mismo sentido. Llamaré a obligatorio, prohibido y permitido valores deónticos. A un código normativo (corpus, ley, ordenamiento, sistema) en el que cada estado de cosas está deónticamente permitido lo llamaré cerrado o completo. Si no está cerrado lo llamaré abierto o diré que tiene lagunas.

¿Existen códigos normativos sin lagunas?

Es inconcebible que una autoridad empírica haya asignado un valor normativo a todos los estados de cosas posibles. Necesariamente habrá estados de cosas individuales a los que el Derecho positivo no declare ni permitidos ni prohibidos (en realidad, la gran mayoría de los estados de cosas pertenecen a esta categoría). En este sentido, la respuesta a la anterior pregunta es negativa.

La existencia de lagunas, sin embargo, puede ser considerada insatisfactoria desde el punto de vista del legislador y -no menos- desde el punto de vista del destinatario de las normas, por lo que el legislador puede querer remediar la situación adoptando alguna metanorma de cierre del sistema normativo, de la misma manera que puede adoptar metanormas para enfrentarse a posibles contradicciones.

Consideremos el supuesto siguiente: Existe un estado de cosas $p$ que está permitido. Asumamos que es también obligatorio. Entonces el estado contradictorio, $\sim p$, está, por definición, prohibido (y, por tanto, deónticamente determinado). Asumamos ahora que el estado permitido $p$ no es también obligatorio. En ese caso, ¿debe estar asimismo deónticamente determinado el estado contradictorio $\sim p$ ? Si el código normativo es consistente, no puede estar prohibido. Pero ¿debe estar permitido? La respuesta es que "debe" estarlo sólo en virtud de una estipulación metanormativa. Esta estipulación parecería razonable, porque en su ausencia los destinatarios de las normas no tendrían la seguridad de si pueden abstenerse de usar el permiso dado de producir $p$. 
Una metanorma que asegure que, si un estado de cosas está deónticamente determinado, entonces el estado contrario está determinado también, avanzaría un pequeño paso en la dirección de hacer que el código sea completo, pero hay otras formas de conseguir este mismo fin efectivamente.

15

¿Qué quiere decir que algo está permitido? Esta cuestión plantea un problema antiguo y muy debatido en la filosofía del Derecho y la filosofía de las normas en general. Muchos filósofos han sostenido que un "permiso" consiste sólo en la ausencia de una prohibición, y probablemente es correcto decir que la mayoría de los lógicos deónticos han compartido esta opinión. Yo mismo he sostenido esto en mis primeras publicaciones sobre este tema, guiado por una cierrta analogía entre los conceptos deónticos y los modales. De la misma manera que la posibilidad es la negación de la necesidad de lo contradictorio de una proposición, la permisión es la negación de la obligatoriedad de lo contradictorio. $P p \leftrightarrow \sim O \sim p$ es un teorema de la lógica deóntica clásica.

Creo que esta tesis está equivocada. La relación entre la permisión y la ausencia de prohibición no es una relación conceptual, sino normativa. Puede haber buenas razones para hacer un código (ordenamiento) normativo cerrado, estipulando que todo lo que no está prohibido por las normas del sistema está por ello permitido. Pero declarar permitido a lo no prohibido es un acto normativo; lo que lo establece es una metanorma (jurídica). Los conocidos principios nulla poena sine lege y nullum crimen sine lege pueden considerarse versiones de esta metanorma, o al menos como principios estrechamente relacionados con ella.

Una metanorma de acuerdo con la cual todo lo que no está prohibido, está permitido podría cerrar un código normativo, pero ¿no podría existir también una metanorma, con el mismo efecto, de acuerdo con la cual todo lo que no estuviera permitido estuviera ipso facto prohibido?

Supongamos que $p$ es un estado de cosas tal que ni él mismo ni su contradictorio $\sim p$ estuvieran permitidos (como ya he indicado, en la "vida real" la mayoría de stados caen en esta categoría). Si el metateorema dice que lo que no está permitido, está prohibido, el código normativo contendría tanto $O p$ como $O \sim p$. Habría, por tanto, una contradicción normativa en este código, lo que, obviamente, resulta insatisfactorio. ¿Quiere esto decir que la metanorma que estamos considerando debe ser rechazada por absurda o por destruir el ordenamiento normativo? 
En esta forma cruda, la metanorma es absurda, pero la idea de que lo no permitido está prohibido puede ser reformulada de manera que sea inteligible y, quizá, incluso aceptable en algún código normativo o en alguna parte de él.

Como vimos en la sección 3, una norma que en nuestro simbolismo "primitivo" se formule como "Op" cubre diferentes casos que sólo podríamos distinguir con un formalismo más desarrollado. Así, $O p$ puede ser un mandato de producir el estado $p$, o una prohibición de destruirlo, o un mandato de conservarlo, si de otro modo desaparecería, o, por último, una prohibición de impedirlo, si de otra manera llegaría a ser. $O \sim p$ puede ser un mandato de destruirlo, una prohibición de producirlo, un mandato de impedirlo o una prohibición de conservar el estado de cosas en cuestión.

Igualmente, $P p$ cubre cuatro casos: un permiso de producir $p$, un permiso de dejar que continúe siendo, un permiso de impedir que desaparezca o un permiso de dejar que se origine. $P \sim p$, a su vez, puede ser un permiso de destruir $p$, un permiso de dejar que continúe ausente, un permiso de impedirlo o un permiso de dejar que desaparezca.

Si ahora se entiende tácitamente que $P p$ abarca sólo un permiso de producir $p$, y $P \sim p$ un permiso de destruirlo, entonces, en ausencia de ambos permisos, la metanorma diría que está prohibido producir algo y, también, destruir el estado en cuestión. Y esto no es una contradicción normativa. De forma similar, si se considera que $P p$ abarca sólo el permiso de dejar que el estado continúe siendo ("no tocarlo"), y $P \sim p$ el permiso de dejar que permanezca ausente, entonces, en ausencia de ambos permisos, la metanorma dice que está prohibido dejar el estado sin destruir (si está presente) y, también, dejarlo sin producir, si está ausente. En otras palabras, indica que el estado de cosas debe ser destruido si está presente y producido si no lo está. Estas dos obligaciones no son normativamente inconsistentes entre sí, pero como la satisfacción de una crea una situación en la cual la otra también debe ser satisfecha, su aparición conjunta en un sistema normativo también puede ser considerada como "lógicamente torpe". He llamado a los mandatos de este tipo "órdenes Sísifo"1.

Dejaré al lector que descubra qué prohibiciones existirían en virtud de la metanorma si $P p$ y $P \sim p$ se encuentran en el código con alguna de las restantes interpretaciones posibles. La metanorma que dice que lo no permitido está ipso facto prohibido sólo conduce a una contradicción normativa en el caso de que se interprete que los dos permisos abarcan todos los casos incluidos en la misma formulación.

\footnotetext{
${ }^{1}$ Norm and Action, p. 147 (Routledge \& Kegan Paul, Londres, 1963).
} 
¿Qué diferencia hay "en la práctica" entre que un estado de cosas no esté prohibido y que esté permitido? Supongamos que no hay una norma $P p$ en un sistema normativo. Ahora alguien produce este estado de cosas. ¿Cuál debería ser la reacción del legislador? Podría decir: "No tenías permitido hacer eso y no debes hacer lo que no está permitido (por mí)", apelando de esta forma a una metanorma según la cual todo lo que no está permitido está por ello prohibido. Desde el punto de vista de la lógica normativa esto sería posible, aunque quizá menos razonable que si el legislador hubiera dicho: "puesto que no estaba prohibido (por mí) hacer esto, tú eres libre de hacerlo". Pero se puede pensar también en un caso intermedio respecto de la adopción de alguna de estas metanormas. El legislador podría haber dicho que, si algo no está permitido por alguna norma del sistema, un sujeto que se plantea hacer tal cosa debe "pedir permiso" al legislador para hacerlo. Éste puede en ese momento prohibir o permitir hacerla. Tal "metanorma" es a veces impuesta por los padres a sus hijos, o por los educadores a aquellos a quienes educan.

En realidad, los legisladores también pueden inclinarse por asumir un papel "paternalista" hacia aquellos para quienes legislan. A veces, esto puede ser razonable. Tener un permiso-carte blanche para hacer todo aquello que no está efectivamente prohibido puede parecer excesivamente "generoso". Los avances en ciencia y tecnología hacen posible cosas que previamente era imposible de realizar por medio de la acción o interferencia humana. En momentos de rápido cambio puede ser poco deseable permitir todo lo que el legislador todavía no ha considerado "desde el punto de vista normativo". Por tanto, al menos para algunas categorías de estados de cosas puede ser prudente adoptar una metanorma que establezca que, en caso de que tales estados de cosas lleguen a ser o a ser posibles, antes de hacerlos se debe tener un permiso. Se puede pensar, por ejemplo, en las posibilidades de manipulación genética.

He argumentado que las conectivas oracionales se aplican a normas (a oraciones que expresan normas) sólo cuando es posible desplazarlas desde delante de la formulación normativa hasta delante de su contenido. Pero hasta aquí hemos asumido que las conectivas se aplican sin restricciones a los contenidos.

Sin embargo, incluso ésta es una verdad con importantes matizaciones. Aparentemente, esto no ha sido advertido en el pasado por la mayoría de los lógicos deónticos, incluyéndome a mí. 
El principal problema lo constituyen las obligaciones y los permisos disyuntivos, esto es, las normas-obligación y normas-permisión cuyo contenido es la disyunción de estados de cosas. Por ejemplo: $O(p v q)$ y $P(p v q)$.

Consideremos el permiso "puedes abrir la puerta o la ventana". Parece claro que si se dirigiese a alguien un permiso con esas palabras, el sujeto entendería que puede abrir la ventana pero puede también abrir la puerta (o hacer ambas cosas, a menos que tenga razones para pensar que "o" tenga un significado excluyente). Dado que no se le ordena, sino que se le permite hacer ambas cosas, también es libre de elegir cuál de ellas hará, si no hace ambas. Un permiso que tenga aproximadamente esta forma se entendería que significa también -a menudo, pero no siempre- una orden de hacer al menos una de las dos cosas, esto es, una prohibición de dejar ambas cosas sin hacer.

Dado que la obligación implica la permisión, $O(p v q)$ implica $P(p v q)$, de lo que se sigue que también las obligaciones disyuntivas se entenderían normalmente como permitiendo hacer todos los disyuntos de su contenido. Que esto es así puede verificarse fácilmente con ejemplos. Si me dicen que debo abrir la puerta $o$ la ventana, entenderé con naturalidad que esto quiere decir que debo hacer al menos una de las dos cosas, pero que soy libre de (tengo permiso para) elegir cuál de ellas.

Estas observaciones sobre las obligaciones y los permisos disyuntivos no deben ser entendidas como afirmaciones de que, por ejemplo, $P(p v q)$ y $O(p v q)$ implican $P p$ y $P q . O(p v q)$ y $P(p v q)$ son normas lógicamente compatibles con $O \sim p$ (la norma-negación de $P p$ ) y también con $O \sim p$, aunque no con ambas.

Introduciré aquí la noción de sugerencia y diré que un permiso disyuntivo sugiere que los disyuntos individuales de su contenido están permitidos, esto es, que el sujeto normativo puede elegir libremente cuál de ellos realizar (si hace alguno).

La noción de sugerencia no es una relación lógico-normativa entre normas, sino que captura un rasgo semántico del lenguaje normativo. La expresión "permitido que sea $p$ o $q$ ", y también "debe ser $p$ o $q$ ", cuando la consideramos de manera aislada de otras formulaciones normativas dirigidas al mismo sujeto, se entendería como diciendo que cualquiera de los estados de cosas está permitido.

(Podría existir una metanorma en un sistema de acuerdo con la cual los disyuntos de las permisiones u obligaciones disyuntivas están individualmnte permitidos, a menos que haya otras normas en el sistema que prohíban alguno de los disyuntos. Pero la existencia de una metanorma como ésta depende de las decisiones del legislador y no se sigue del análisis del lenguaje normativo). 
Ahora supongamos que el código contiene una norma $P(p v q)$ y otra norma $O \sim p$. Tenemos, por tanto, dos formulaciones normativas, "está permitido el caso de que $p v q$ " y "debe ser el caso de que no $p$ ". Alguien que se encuentre con ellas, por ejemplo en un texto jurídico, seguramente se quedaría perplejo: la primera formulación parece permitir un estado de cosas que la segunda prohíbe expresamente.

Supongamos que se descubre que primero existía el permiso $P(p v q) \mathrm{y}$ después el legislador prohibió $p$. El conjunto compuesto por $P(p v q)$ y $O \sim p$ es consistente. Por tanto, implica, además, $P q$. La forma natural de interpretar esto consiste en pensar que el permiso disyuntivo original ha sido limitado o restringido por el legislador al prohibir uno de los disyuntos. Sería apropiado (linguísticamente) si éste eliminara la formulación $P(p v q)$ del texto jurídico y la reemplazara por $O \sim p$ y $P p$.

Supongamos a continuación que primero existía la prohibición $O \sim p \mathrm{y}$ después el legislador estableció el permiso $P(p v q)$. La manera más natural de interpretar la nueva situación consiste en considerar derogada la prohibición de $p$. Si esto es correcto, el legislador debería eliminar del texto jurídico la formulación de la prohibición previa para evitar confusiones a los sujetos destinatarios de las normas.

$\mathrm{Y}$, finalmente, supongamos que las dos normas, $P(p v q)$ y $O \sim p$ fueron promulgadas al mismo tiempo, o que por alguna otra razón no podemos determinar su orden cronológico: "Está permitido que sea el caso de que $p v q$ pero no debe ser el caso de que $p$ ". Es tentador decir en este supuesto que "la formulación es ininteligible", o preguntar "¿Qué es lo que quiere el legislador?", o señalar que "La ley parece inconsistente: nos garantiza libertad para hacer algo y luego nos la niega" o que "El legislador se comporta irracionalmente".

He tratado de mostrar de qué manera las obligaciones y las permisiones disyuntivas de un sistema normativo son "incompatibles" con prohibiciones de (alguno de) sus disyuntos. Sin embargo, ésta no es una incompatibilidad de lógica normativa. Es mejor llamarla un uso inapropiado del lenguaje normativo, que debería evitarse y que puede ser corregido por medio de las reformulaciones apropiadas. Sería interesante conocer en qué medida los textos jurídicos se muestran cuidadosos con estas cuestiones y evitan "sugerir" que están permitidas cosas que, en realidad, están prohibidas.

Volvamos, por última vez, a la Paradoja de Ross.

Esta paradoja está relacionada con las Paradojas de la Implicación, pero es mucho más "fuerte". Decir que "debes enviar la carta" implica "debes enviar o quemar la carta" resulta seguramente mucho más paradójico que decir 
que "la carta ha sido enviada" implica "la carta ha sido enviada o quemada". ¿Por qué? Creo que la respuesta es bastante clara: la orden disyuntiva normalmente se entendería como permitiéndonos elegir libremente entre dos alternativas. $O p$ implica $O(p v q)$, que, a su vez, implica $P(p v q)$. En ausencia de prohibiciones específicas, se pensaría que $P(p v q)$ permite tanto $q$ como $p$, y entonces puede llegarse a pensar que se podría derivar cualquier permiso arbitrario a partir de $O p$ (no hay ninguna tentación similar de pensar que, puesto que $p$ implica $p v q$, también implica $q$ ).

El ejemplo de Ross tiene una característica que aumenta aún más la impresión de paradoja. Los actos de enviar y de quemar una carta son excluyentes. Si se envía una carta, no se ha quemado, y si se quema, no se puede enviar. Ahora las dos normas- $O, O p$ y $O(p v q)$, son conjuntamente equivalentes a la norma- $O(p \&(p v q))$, y ésta a su vez a $O(p \& \sim q v p \& q)$. Pero $p \& q$, en el ejemplo de Ross, es un estado de cosas imposible. Por ello, la única manera por la que el receptor de las dos órdenes, "¡envía la carta!" y "¡envía o quema la carta", puede satisfacerlas a ambas es enviando y no quemando la carta. Cuando uno advierte esto, la paradoja queda más "mitigada".

Una observación final. Lo paradójico de la situación que Ross advirtió se debe en parte a una incomprensión de la noción de implicación entre normas. Como hemos visto en la sección 11, el hecho de que una norma implique otra no significa que si la primera es verdadera la segunda lo es también, ni que si la primera ha sido emitida (existe) la segunda ha sido, al menos implícitamente, emitida también. Que la obligación de enviar una carta implica la obligación de enviarla o quemarla significa "sólo" que la primera es (sería) incompatible con un permiso de no enviar la carta y hacer otra cosa. Que esto sea así es perfectamente natural y obvio, y de ninguna manera "paradójico". El receptor de la orden "¡envía la carta!" no es también, en virtud de algún "juego de manos" de los lógicos deónticos, receptor de la orden "envía la carta o quémala".

En este trabajo he tratado de mostrar que hay algo que puede llamarse genuinamente "lógica de las normas". Su posibilidad depende de la posibilidad de darle sentido a las nociones de conjunto consistente de normas- $O$ y normas- $P$ y de norma-negación de una norma dada. A partir de estas nociones se pueden definir también las de contradicción e implicación entre normas.

No me parece que haya buenas razones para negar la consideración de lógicas a estas nociones de consistencia, contradicción e implicación, pero es importante ser consciente de los peligros de malinterpretarlas. 
Está implícito en las consideraciones hechas aquí que unas estructuras sintácticas como las "clásicas" y la mayoría de los sistemas de lógica deóntica no son genuinas "lógicas de las normas". La principal razón es que las conectivas oracionales, salvo cuando se desplazan de delante de los operadores $O$ y $P$ a los contenidos normativos que les siguen, no se aplican a las expresiones de normas.

Un cálculo como el que elaboré en mi artículo de 1951 es, en el mejor de los casos, una lógica de lo que he llamado "proposiciones normativas", esto es, de proposiciones verdaderas o falsas que se refieren a la existencia de tal o cual norma. Pero una lógica así no puede pretender ser una representación adecuada de los sistemas normativos existentes. Esto es así porque excluyen las contradicciones y las lagunas de los códigos. Intentar hacer esto "sobre bases lógicas" es inútil. Se puede pensar en varias metanormas para enfrentarse a las contradicciones y las lagunas -o decidir caso por caso lo que debe hacerse con ellas. Las metanormas, algunas de las cuales son bien conocidas por la teoría y la práctica jurídicas tradicionales, no son leyes de la lógica de las normas.

Pero aunque los sistemas clásicos no representan adecuadamente las estructuras normativas existentes, pueden tener otra función: concretamente, la de constituir modelos ideales de lo que ha de ser un sistema libre de contradicciones y de lagunas. Modelos ideales similares, en forma de sistemas de lógica deóntica, pueden también proporcionar estructuras normativas que prevengan lagunas, e incluso de estructuras normativas que puedan solucionar contradicciones.

(Trad. de Daniel González Lagier) 